Nota Clínica

\title{
Plasmocitoma endobronquial
}

M. Estors Guerrero ${ }^{1}$, A. Blanco Orozco, J. L. López Villalobos, C. López García, A. Arnau Obrer ${ }^{1}$, A. Ginel Cañamate

\section{Resumen}

El plasmocitoma extramedular se define como un tumor poco frecuente de células plasmáticas originado primariamente en tejidos blandos (extraóseos) en ausencia de enfermedad generalizada. La localización pulmonar es extremadamente rara, supone el $5 \%$ de los mismos.

Existen pocas aportaciones a la literatura sobre esta entidad. Presentamos un caso clínico de plasmocitoma endobronquial en una mujer de 67 años que debutó con un cuadro de neumonía y derrame paraneumónico de repetición. Fue tratado con ablación con láser mediante broncoscopio rígido. Los controles fibrobroncoscópicos posteriores y el seguimiento clínico y analítico posterior confirman la ausencia de enfermedad 14 meses después de su diagnóstico.

\section{Palabras clave:}

Plasmocitoma endobronquial. Plasmocitoma extramedular. Broncoscopio rígido

Oncología, 2006; 29 (5):223-226

\section{Summary}

Extramedullary plasmacytoma is a little frequent plasma cell tumor originating mainly in the soft tissues (extramedullary) in the absence of generalized disease. Lung localization is very rare, comprising $5 \%$ of the cases.

There are few literature contributions about this entity. We present a clinical case of endobronchial plasmacytoma of a 67 year old woman presented with a picture of pneumonia and recurrent parapneumonic efussion. She was treated with laser ablation using a rigid bronchoscope. The subsequent fibrobronchoscopic controls and the clinical and analytical follow up confirmed the absence of disease 14 months after the diagnosis.

Key words: Endobronchial plasmacytoma. Extramedullary plamacytoma. Rigid bronchoscopy.

Servicio de Cirugía Torácica

${ }^{1}$ CHGU. Valencia 


\section{Introducción}

El plasmocitoma pulmonar es extremadamente raro, supone el 5\% de los plasmocitomas extramedulares, definidos estos como tumores poco frecuentes de células plasmáticas originados primariamente en tejidos blandos, sobretodo en cabeza y cuello, constituyendo el crecimiento endobronquial una localización atípica ${ }^{1}$. El diagnóstico del mismo no se halla exento de dificultades siendo esencial el análisis inmunohistoquímico. Es la exéresis del tumor el tratamiento de elección. El seguimiento clínico y analítico posterior es fundamental para poder detectar posibles recidivas locales o sistémicas ${ }^{2} \mathrm{cu}-$ ya frecuencia no es despreciable.

Existen pocas aportaciones a la literatura sobre esta entidad. Presentamos un caso clínico de plasmocitoma endobronquial tratado con ablación con láser mediante broncoscopio rígido.

\section{Observación clínica}

Mujer de 67 años de edad con hipertensión esencial y dislipemia como únicos antecedentes de interés. Presenta en un intervalo de tiempo de 3 meses dos cuadros de neumonía con derrame paraneumónico en L.I.D., ambos resueltos con tratamiento antibiótico y drenaje endotorácico. Ante esta situación decidimos ampliar el estudio. Se realiza una TC que nos informa de la presencia de una tumoración endobronquial a nivel de bronquio intermedario derecho (Figura 1) y neumonitis obstructiva del L.I.D.

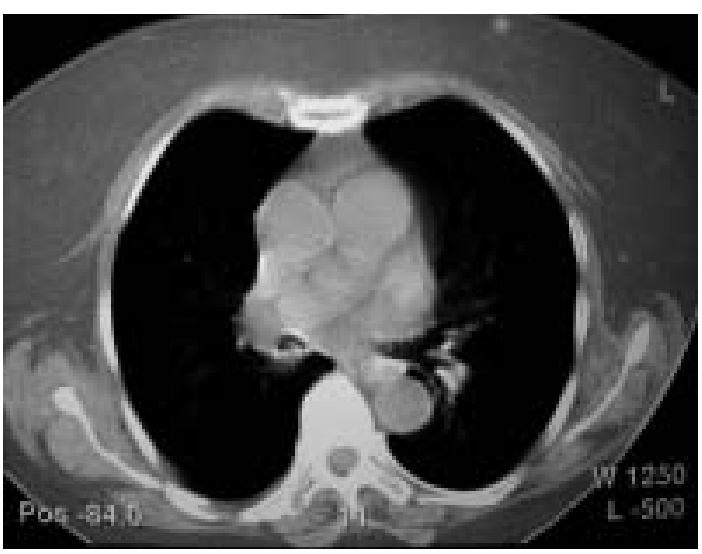

Figura 1. Tumoración endoluminal a nivel lóbulo intermediario derecho.

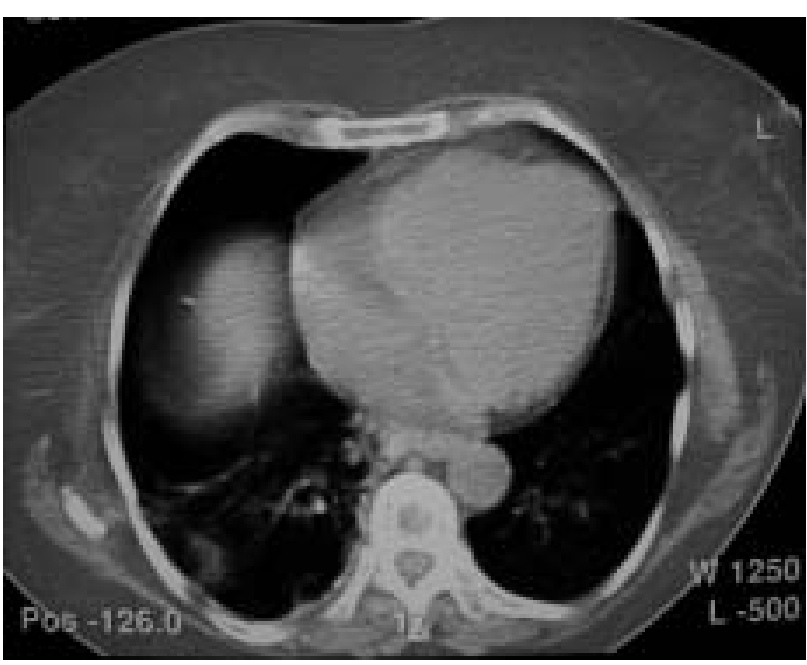

Figura 2. Neumonitis obstructiva.

(Figura 2). Mediante el fibrobroncoscopio se apreció dicha tumoración, redondeada (con un diámetro de $1-1.2 \mathrm{~cm}$ ) y perlada que sangraba con facilidad por lo que no se tomaron muestras para biopsia. Así pues, ante la ausencia de histopatología previa y la sospecha de tumor carcinoide por características macroscópicas se optó por la resección de la lesión con láser mediante broncoscopio rígido. En el mismo acto quirúrgico se colocó una prótesis de poliflex en bronquio intermediario derecho dejando expedita la salida L.M., segmento 6 y basales. Células gigantes megacariocíticas y células propias del mieloma junto a la positividad para CD45, IGg y débil para Kappa en el estudio histológico concluyeron el diagnóstico de plasmocitoma. La biopsia de médula ósea, hemograma, bioquímica, elemental de orina, electroinmunoféresis sanguínea y de orina y el rastreo óseo, pruebas todas ellas realizadas tras el diagnóstico histológico no mostraron alteraciones patológicas lo que nos permitió emitir el diagnóstico de plasmocitoma extramedular.

La prótesis bronquial fue retirada 3 meses después de su colocación sin ninguna incidencia. Los controles fibrobroncoscópicos posteriores y el seguimiento clínico y analítico confirman la ausencia de enfermedad 14 meses después.

\section{Discusión}

El plasmocitoma endobronquial es extremadamente raro, supone el 5\% de los plasmocitomas ex- 
tramedulares. Podemos definir el plasmocitoma extramedular como un tumor poco frecuente de células plasmáticas originado primariamente en tejidos blandos (extraóseos) en ausencia de enfermedad generalizada. Su incidencia es del $1 \%$ y representa el 4\% de las neoplasias de células plasmáticas. Es más frecuente en hombres que en mujeres con una relación $3-5: 1^{3}$. Suele presentarse durante la $6^{\mathrm{a}}-7^{\mathrm{a}}$ década. En el $90 \%$ de los casos se localizan en cabeza y cuello (fosa nasal, seno maxilar y nasofaringe) ${ }^{4}$, otras localizaciones son pulmón (5\%), ganglios linfáticos $(5 \%)$, tracto gastrointestinal y piel. Típicamente en pulmón se presenta como nódulo pulmonar solitario, menos frecuente como consolidación pulmonar o en forma de infiltrados difusos ${ }^{5}$. Sin duda el crecimiento endobronquial constituye una localización atípica. En una revisión de la literatura ${ }^{1}$, encontramos 22 casos de plasmocitoma pulmonares, 5 de los cuales fueron endobronquiales.

La clínica es secundaria al crecimiento local del tumor. En nuestro caso cursó con dos cuadros de neumonía consecuentes a una obstrucción bronquial y neumonitis obstructiva. Se ha relacionado típicamente con el síndrome de POEMS (polineuropatía, organomegalia, endocrinopatía, proteínas monoclonales y cambios cutáneos) y más recientemente con el síndrome de $\mathrm{AESOP}^{6}$ (adenopatías y alteraciones cutáneas extensas con plasmocitoma subyacente).

El diagnóstico es fundamentalmente histológico, en ocasiones existen dificultades para diferenciarlo de granulomas de células plasmáticas, pseudolinfomas y otras reacciones granulomatosas. Son los estudios inmunohistoquímicos con restricción de cadena ligera Kappa o Lambda los que nos confirman el diagnóstico ${ }^{1}$. No podemos hablar de plasmocitoma extramedular sin que los resultados de los estudios de enfermedad diseminada sean negativos. Un rastreo óseo, biopsia de médula ósea y electroinmunoféresis sanguínea y de orina dentro de la normalidad excluyen las alteraciones propias de mieloma múltiple ${ }^{1}$. La determinación del componente $\mathrm{M}$ es de gran utilidad ya que este se normaliza tras el tratamiento y su presencia posterior constituye un marcador de recurrencia ${ }^{2}$. En estudios retrospectivos aparece en un $25 \%$ en sangre y $3 \%$ en orina.

La excisión quirúrgica constituye el tratamiento de elección en combinación con quimiorradioterapia adyuvante en el caso de que existan lesiones residuales o recidivas, proporciona larga superviven- cia $^{3}$ (40-75\% están libres de enfermedad a los 10 años, la media de supervivencia es de 100 meses). De los 5 casos de plasmocitoma endobronquial descritos en la literatura, 3 de ellos se trataron con lobectomía, 2 con ablación broncoscópica con láser, que éste es el mismo tratamiento que adoptamos para nuestra paciente, uno de ellos tras quimiorradioterapia previa.

Por último mencionar que es imprescindible un buen seguimiento del paciente tras el tratamiento ya que no son infrecuentes las recidivas tanto locales, que pueden anunciar la diseminación tumoral ${ }^{4}$, como sistémicas (35-50\%), sobretodo de vías aéreas bajas, pulmón, tubo digestivo y piel que metastarizan más rápido y presentan peor pronóstico así como la progresión a mieloma múltiple (20-30\%).

Concluímos, la ablación con láser evita la morbilidad que deriva de la cirugía pulmonar y aunque no existan estudios comparativos debería considerarse en pacientes con plasmocitoma pulmonar, sobretodo especialmente en aquellos con función pulmonar limitada y siempre que la tumoración sea accesible al broncoscopio rígido y láser.

Correspondencia:

Dra. M. Estors Guerrero

Servicio de Cirugía Torácica

Hospital General Universitario de Valencia

Avenida Tres Cruces, s/n

E-46014 Valencia

miriamestors@terra.es 


\section{Bibliografía}

1. Evgeny Edelstein, MD, Anthony A.Gal, MD, Karen P. Mann; MD, Joseph I.Miller, Jr, MD, Kamal A. Mansour, MD. Primary Solitary Endobronquial Plasmacytoma. Ann Thorac Surg 2004;78:1449-51.

2. García Franco CE, Jiménez Hiscock L, Zapatero Gaviria J. Plasmocitoma costal solitario. Arch Bronconeumol 2004; 40:100-1.

3. Wasserman TH. Diagnosis and management of plasmacytomas. Oncology 1987;1:37- 40.

4. Mochimatsu I, Tsukuda M, Saeald S, Nakatani Y. Extremedullary plasmocytoma of the larynx. J Laringol Otol 1993;107:1049-51.

5. Koss MN, Hochholzer L, Moran CA, Frizzera G. Pulmonary plasmacytomas: A clinicopathologic and inmunohistochemical study of five cases. Ann Diagn Pathol 1998;2:1-11.

6. Lipster D, Roudeau M, Massard G, Grosstrons E. The AE-
SOP (adenopathy and extensive skin patch overling a plasmacytoma) syndrome: report a 4 cases a new syndrome revealing POEMS (polineuropathy, organomegaly, endocrinopathy, monoclonal protein and skin changes) syndrome at a curable stage. Medicine 2003;82:51-9.

7. Geetha Joseph, MD; Manjula Pandit, MD, Linda korfhage, MD. Primary Pulmonary Plasmacytoma. Cancer 1993;71:721-4.

8. Brackett LE, Myers JR, Sherman CB. Laser treatment endobronchial extramedullary plasmacytoma. Chest 1994;106:1276-7.

9. Incarbone M, Pastorino U. Surgical treatment of chest wall tumors. World J Surg 2001;25:218-30.

10. Gegova A, Kunev K, Popkhristova T, Lerziev I. Plasmacytomas of the upper respiratory tract. Khirurgiia Sofiia 1995;48(6):16-8. 